\title{
The concentration of homocysteine in patients after ischemic brain stroke and vascular dementia
}

\author{
Nafija Serdarević1* ${ }^{*}$ Lejla Begić ${ }^{2}$, Adaleta Mulaomerović - Softić² \\ 1 Department for Clinical Chemistry, University of Sarajevo Clinical Center, Bolnička 25, 71000 Sarajevo, Bosnia and Herzegovina. \\ ${ }^{2}$ Department of Biochemistry, Faculty of Pharmacy, University of Tuzla, Univerzitetska 8, 75000 Tuzla, Bosnia and Herzegovina.
}

\begin{abstract}
Introduction: The aim of this study is to examine whether moderate hiperhomocysteinemia is an independent risk factor for cerebral infarction.

Methods: We have measured homocysteine levels in 50 patients with ischemic stroke during acute phase and postacute phase, 50 patients diagnosed with vascular dementia and healthy group of 50 subjects. Homocysteine concentration in serum was measured, on the basis of fluorescent polarisation measuring.

Results: The study demonstrated that homocysteine concentration was $16.93 \mu \mathrm{mol} / \mathrm{L}$ in the patient group with ischemic stroke, and in the group of patients with vascular dementia was $20.39 \mu \mathrm{mol} / \mathrm{L}$. Homocysteine increases during the postacute phase of ischemic stroke after 7 days for $1.54 \mu \mathrm{mol} / \mathrm{L}$ and 14 days for $3.66 \mu \mathrm{mol} / \mathrm{L}$ compared to the concentration of homocysteine after the first hours of hospitalization. Using Wilcoxon signed ranks and Mann-Whitney $(P<0.05)$ tests we got significant difference between homocysteine concentration at acute phase and post-acute phase of ischemic stroke and it was significant difference between concentrations of homocysteine in the acute and post-acute phase of ischemic stroke and vascular dementia. The Spearman correlation test was found significant correlation between the number of strokes and the concentration of homocysteine in serum of patients with vascular dementia.

Conclusions: The homocysteine concentration rises significantly during of acute phase of ischemic brain stroke, and it is significantly increased during post-acute phase, which is a predictor factor for further development of vascular dementia, or a new ischemic brain stroke.
\end{abstract}

(c) 2011 University of Sarajevo Faculty of Health Studies

Keywords: homocysteine, ischemic brain stroke and vascular dementia.

\section{Introduction}

The ischemic stroke (IS) is major cause of global disability and is the second most common cause of death worldwide. Elevated tolal plasma homocysteine level is common in the old age and is well-established risk factor for cardiovascular and cerebrovascular disease (1). The amino acid homocysteine occurs by demethylation of methionine, essential amino acid, which in enters the human body with food. It is found in the plasma mainly in the oxidized state (homocysteine or homocysteine-cysteine disulfide) and bound to proteins, mostly albumin $(2,3)$. It was first described in work of Butz and Vigneaud who have synthesized amino acid homocysteine in a reaction of strong concentrated acid with methionine. (4). Based on findings

\footnotetext{
* Corresponding author: Nafija Serdarević; Institute for Clinical Chemistry and Biochemistry, University of Sarajevo Clinics Center, Bolnička 25, 71000 Sarajevo, Bosnia and Herzegovina; Phone: +38733663353 , Fax: +38733663353; E-mail: serdarevicnafija@yahoo.com
}

Submitted 21 January 2011 / Accepted 25 February 2011 observed in patients with homocystinuria, McCully postulated that hyperhomocysteinemia may play a role in the pathogenesis of atherotrombotic vascular disease (5). Elevated levels of homocysteine can therefore cause damage to several key pathways in the central nervous system, either directly or by changing the methylation potential. The hyperhomocysteinemia is very common in patients with stroke and is suggested to be an independent risk factor for the disease $(6,7)$. The elevated concentrations of homocysteine are responsible for occurrence of atherosclerosis in at least 3 ways: 1) toxic effect of homocysteine in endothelium of arteries, 2) interference of homocysteine with clotting factors and 3) oxidation of low-density lipoprotein (LDL). Although there are data on homocysteine metabolism, the pathogenesis of hyperhomocysteinemia is still not clear. Homocysteine is turned into a methionine by remethylation; methyl group donor in most tissues is 5 -methyltetrahydrofolate, nevertheless betaine is donor in the liver, kidney and eye lens. The reaction is catalyzed by methionine-synthase (MS) with vitamin 
B12 as a cofactor. Tetrahydrofolate incurred converts to 5,10-methyl-tetrahydrofolate with the enzyme methylene-tetrahydrofolate reductase (MTHFR) and then in 5-methyl-tetrahydrofolate. Another pathway of homocysteine metabolism is trans-sulphuration pathway in which homocysteine with serine turns to cystathionine under the action of enzymes cistationine- $\beta$-synthase (CBS) and cofactor vitamin B6. After that cystathionine goes into cysteine under the influence of the enzyme $\gamma$-cystathionase (GCT) (8-10). Homocysteine metaboli$\mathrm{sm}$ is regulated by the concentration of methionine that is normally used for protein synthesis and synthesis of S-adenosyl-methionine. Homocysteine lies at the intersection two of metabolic pathways, transsulphuration pathway and remethylation cycle. Current availability of methionine determines the pathway by which the homocystein will be metabolized. Decrease of folic acid and vitamin B12 leads to increase of homocysteine and decreases the remethylation of homocysteine $(11,12)$. It could be postulated that elevated total homocysteine is a risk factor for atherotrombic stroke in particular. Moreover, there is a debate whether homocysteine is a causative risk factor in stroke and myocard infarction or is merely a secondary marker of risk in survivors (13). Date regarding to homocysteine concentration immediately after stroke would help to resolve this question, because the observation of a raised homocysteine at this time would be more suggestive of a causal association that the occurrence of hyperhomocysteinemia in survivous sampled at a time distant from the event.

\section{Methods}

\section{Patients}

The investigation included 100 patients and 50 healthy subjects. 250 blood samples were collected during 2008 and 2009. All investigation was done respecting ethical standards by the Helsinki Declaration. The patients were hospitalised at Clinic of Neurology, Clinical Centre University of Sarajevo, Old home "Nedžarići, and Old home "Ernest Grin". The patients group included patients with first ischemic stroke (50 subjects) and vascular dementia (50 subjects). The control group included 50 healthy subjects who were protégé at Old home "Nedžarići". Criteria for inclusion of patients with stroke and vascular dementia were: diagnosis of first ischemic stroke determined by computerized tomography (CT), presence of vascular dementia identified using computerized tomography (CT) and nuclear magnetic resonance (NMR), "Hachinski ischemic score" grater or equal to 7 for patients with vascular dementia, age over 65 years for both sexes, two weeks of hospital stay for patients with ischemic stroke, stroke in patients with vascular dementia in last three to six years. The study inclusion criteria for control group were: excluded ischemic stroke or vascular dementia by computed tomography (CT) and nuclear magnetic resonance (NMR), age over 65 years for both sexes, excluded kidney, heart or vascular diseases. Criteria for exclusion from the study, for both patients and controls, were: diseases that are associated with impaired renal function and renal failure (determined by serum creatinine concentration), chronic inflammatory disease, rheumatoid arthritis, SLE, multiple sclerosis and psoriasis, acute lymphoblastic leukaemia, intestinal disorders atrophic gastritis, Crohn's disease and ulcerative colitis, Hypothyroidism, patients on treatment with methotrexat, carbamazepine, phenytoin, and theophylline. The blood samples were collected at the mornings before the first meal. For the group of 50 patients diagnosed with the first ischemic brain stroke, blood samples were taken during the acute phase (initial 24-48 hospitalization hours), and post-acute phase (after $7 \pm 1$ days, and after 11-14 hospitalization days). For the group of 50 patients diagnosed with vascular dementia developed as a consequence of ischemic brain stroke, i.e. of many small ischemic focus of various age. The study included 27 men and 23 women in control group. There were 27 males and 23 females in the group with ischemic stroke and 28 men and 22 women in the group with vascular dementia. By analyzing the history of disease we collected data about radiological examinations of brain computed tomography (CT) and brain nuclear magnetic resonance (NMR). 92\% (46) of patients suffering from ischemic stroke had the diagnosis $I C V$ per trombosim and at $8 \%$ (4) patients the diagnosis was ICV per emboliam. Level of albumin was obtained from patients history and was in normal range $(35-50 \mathrm{~g} / \mathrm{L})$. The value of serum homocysteine concentration was determined using AxSYM (Abbott), based on measurements of fluorescence polarization immunoassay (FPIA) technology. The reaction principle is conversion of homocystine, mixed disulfide and protein-bound forms of homocysteine in the sample to form of free homocysteine by the use of dithiothreitol (DTT). After that, free homocysteine is converted to S-adenosyl-Lhomocysteine (SAH). Under physiological conditions, SAH hydrolases convert SAH to homocysteine. Levels of L-homocysteine are determined in human serum. Normal homocysteine concentration in serum is 3.36$20.44 \mu \mathrm{mol} / \mathrm{L}$ for women and 5.90-16 $\mu \mathrm{mol} / \mathrm{L}$ for men. The creatinin was determined using automatic analyzer Dimension (Dade Behring). Method for determination of creatinine is a modification of the kinetic reaction of Jaffee. The reference value for serum creatinine concentration is $45-115 \mu \mathrm{mol} / \mathrm{L}$. The patient samples of blood were collected in serum separation Vacutainer test tubes (Beckton Dickinson, Rutherford, NJ 07,070 U.S.) in volume of $3.5 \mathrm{~mL}$. We used test tubes with gel. After collection, samples were placed in ice and, after 30 to 60 
TABLE 1. Serum concentration of homocysteine (Hcy) at patients with ischemic brain stroke, vascular dementia and control group.

\begin{tabular}{lccccc}
\hline & $\begin{array}{c}\text { Patients with ischemic } \\
\text { brain stroke }\end{array}$ & $\begin{array}{c}\text { Patients with ischemic } \\
\text { brain stroke }\end{array}$ & $\begin{array}{c}\text { Patients with ischemic } \\
\text { brain stroke }\end{array}$ & $\begin{array}{c}\text { Patients with vascular } \\
\text { dementia }\end{array}$ & Control group \\
\hline Time of determination & $24-48$ hours & 7 days & 14 days & - & - \\
X $_{\text {sr }}$ & 13.27 & 14.81 & 16.93 & 20.39 & 10.49 \\
S.D. & 5.62 & 6.03 & 7.63 & 10.15 & 1.92 \\
S.E. & 0.79 & 0.85 & 1.07 & 1.43 & 0.27 \\
Number of patients & 50 & 50 & 50 & 50 & 50 \\
\hline
\end{tabular}

minutes serum samples were obtained by centrifugation at $3000 \mathrm{rpm}$ using centrifuge (Sigma 4-10). After centrifuging, concentration of homocysteine and creatinine in sera were determined. All subjects (patients and controls) had concentration of creatinine in reference values.

\section{Statistical analysis}

The results were statistically analyzed using SPSS version 11 and Microsoft Office Excel 2003. Average values $(\bar{X})$, standard deviation $(S D)$ and Spearman correlation coefficient ( $r$ ) were calculated, as well as Wilcoxon signed ranks and Mann-Whitney test with statistical significance level of $0.05(\mathrm{P}<0.05)$.

\section{Results}

The average age in the control group was 69.34 years. In the group with vascular dementia, the average age was 73.74 years. The group with ischemic stroke had an average age of 70.12 years.

Mean concentrations of homocysteine in patients after ischemic stroke (24-48 hours, 7 days and 14 days), patients with vascular dementia and control groups are shown in Table 1. The average concentration of homocysteine and + / - SD in patients after ischemic stroke (24-48 hours, 7 days and 14 days), patients with vascular dementia and control groups are graphically show in Figure 1. The homocysteine serum concentrations were increased during the acute phase to the post acute phase of ischemic stroke, as shown by results in Figure 2. During hospitalization serum concentrations of homocysteine increased after seven days and then increased significantly after the fourteenth day. In the acute phase after 7 days of hospital treatment homocysteine concentration was increased for $1.54 \mu \mathrm{mol} / \mathrm{L}$, after 14 days for 3.66 $\mu \mathrm{mol} / \mathrm{L}$ compared to the concentration after the first 24 48 hours. Between 7 and 14 days of treatment the concentration of homocysteine increases for $2.12 \mu \mathrm{mol} / \mathrm{L}$. Analysis of distribution showed assimetrical distribution of homocysteine levels in patients with ischemic stroke, vascular dementia and control group. We used Wilcoxon signed ranks for comparison of serum homocysteine concentration in patients with ischemic brain stroke during acute phase and post-acute phase. Results are shown in Table 2.

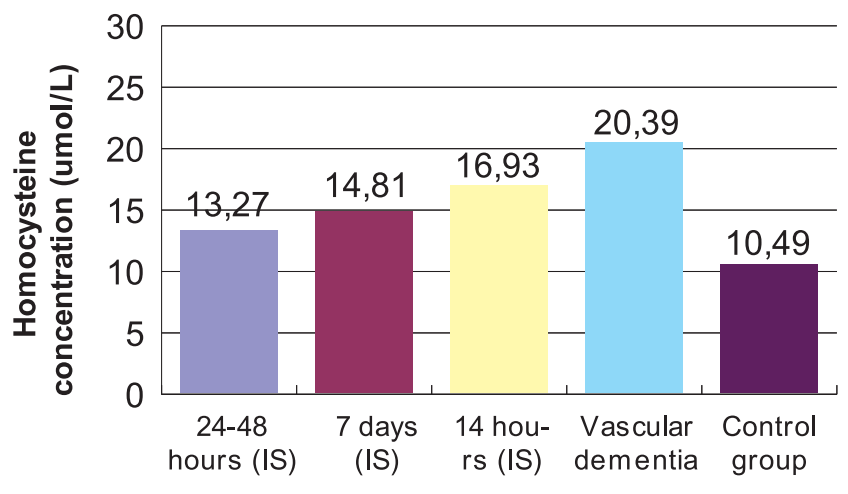

FIGURE 1. The mean serum homocysteine concentration +/S.D in risk of patients (ischemic stroke (IS), vascular dementia) and control group

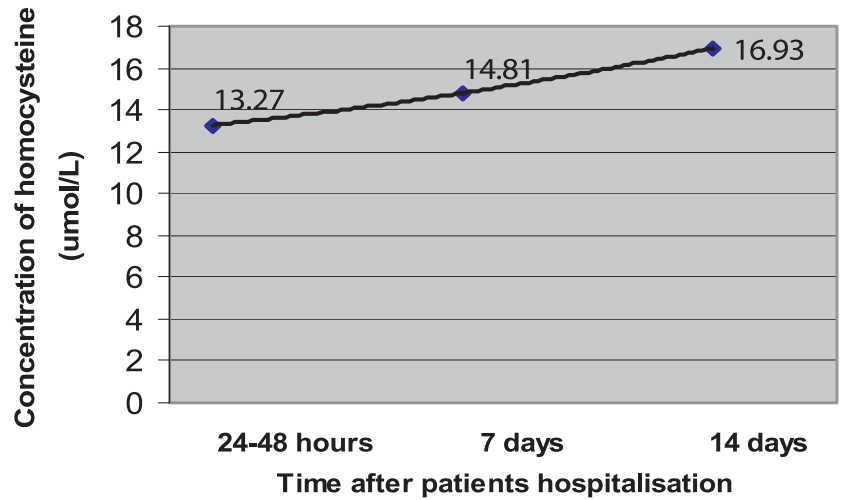

FIGURE 2. Serum concentration of homocysteine in patient with ischemic stroke during acute phase and post-acute phase.

TABLE 2. Comparison of serum homocysteine concentration (Hcy) in patients with ischemic brain stroke during acute phase and post-acute phase

\begin{tabular}{lccc}
\hline & $\begin{array}{c}\text { (after } 7 \text { days) } \\
\text { with (24-48 hours) }\end{array}$ & $\begin{array}{c}\text { (after } 14 \text { days) } \\
\text { with (24-48 hours) }\end{array}$ & $\begin{array}{c}\text { (after 14 days) } \\
\text { with (after } 7 \text { days) }\end{array}$ \\
\hline $\mathrm{Z}$ & -5.850 & -6.1543 & -5.927 \\
$\mathrm{P}$ & $0.000^{*}$ & $0.000^{*}$ & $0.000^{*}$ \\
\hline
\end{tabular}

${ }^{*} P<0.05$ (Wilcoxon signed ranks)

In Table 2. $\mathrm{Z}$ and $\mathrm{P}$ values of average serum homocysteine concentrations in patients during acute and post-acute phase of ischemic stroke are shown. Using Wilcoxon signed ranks test we have concluded that the average 
TABLE 3. Comparison of serum homocysteine concentration (Hcy) in risk group of patients with control group

\begin{tabular}{llccc}
\hline Comparison groups & $\begin{array}{l}\text { Time of deter- } \\
\text { mination }\end{array}$ & $\begin{array}{c}\text { Mann- } \\
\text { Whitney U }\end{array}$ & Z & P \\
\hline $\begin{array}{l}\text { Ischemic brain stroke } \\
\text { with control group }\end{array}$ & $24-48$ hours & 1046.00 & -1.406 & 0.160 \\
$\begin{array}{l}\text { Ischemic brain stroke } \\
\text { with control group }\end{array}$ & 7 days & 696.50 & -3.816 & $0.000^{*}$ \\
$\begin{array}{l}\text { Ischemic brain stroke } \\
\text { with control group }\end{array}$ & 14 days & 335.50 & -6.605 & $0.000^{*}$ \\
$\begin{array}{l}\text { ischemic brain stroke } \\
\text { with vascular dementia }\end{array}$ & $24-48$ hours & 486.00 & -5.267 & $0.000^{*}$ \\
$\begin{array}{l}\text { ischemic brain stroke } \\
\text { with vascular dementia }\end{array}$ & 7 days & 614.50 & -4.381 & $0.000^{*}$ \\
$\begin{array}{l}\text { ischemic brain stroke } \\
\text { with vascular dementia }\end{array}$ & 14 days & 790.50 & -3.168 & $0.002^{*}$ \\
$\begin{array}{l}\text { vascular dementia } \\
\text { with control group }\end{array}$ & & 44.000 & -8.314 & $0.000^{*}$ \\
\hline
\end{tabular}

serum homocysteine concentration 24-48 hours after the first symptoms of ischemic stroke were significantly differed from the concentration of homocysteine after 7 and 14 days of hospital treatment $(\mathrm{p}<0.05)$. There was a significant difference between the average homocysteine concentration after 7 and 14 days of hospital treatment $(\mathrm{p}<0.05)$. Using Mann-Whitney U-test we made comparison of serum homocysteine between risk groups (ischemic stroke, vascular dementia) and control healthy group, the results are shown in Table 3. According to Mann-Whitney test for $\alpha=5 \%$, the difference between concentrations of homocysteine in the acute phase of ischemic stroke and control healthy groups is not significant. The same test for $\alpha=5 \%$ has shown a significant difference between concentrations of homocysteine in the acute phase of ischemic stroke and control group. The serum concentrations of homocysteine increase after 7 days and significantly increased after 14 days of hospital treatment. We found significant difference between concentrations of homocysteine in the acute and the post-acute phase of ischemic stroke and a group with vascular dementia $(p<0.05)$. The concentration of serum homocysteine concentration was higher in the group with vascular dementia than in the group with ischemic stroke. Average serum concentrations of homocysteine in the group with vascular dementia was significantly different from control healthy group ( $\mathrm{p}<0.05)$. The serum creatinene concentration was in reference value (45-115 $\mu \mathrm{mol} / \mathrm{L}$ ) for all patients in risk groups and in control group. So we can exclude that serum concentration of homocysteine was increased for kidney demage. In the group of patients with vascular dementia, 52\% (26 patients) had an extensive one stroke, $32 \%$ (16 patients) two ${ }^{*} P<0.05$ (Mann-Whitney U-test)

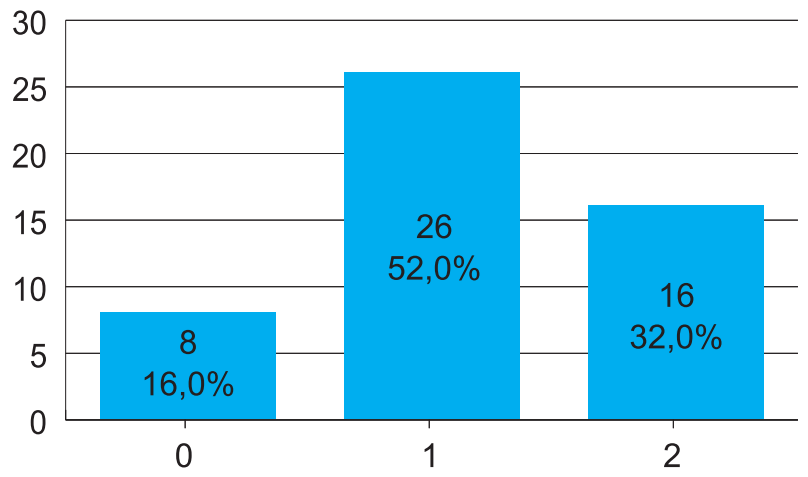

FIGURE 3. Number of brain attacks in patients with vascular dementia. (0- many) small focus i without ischemic stroke (16\%), 1 - one ischemic stroke (52\%), 2- ischemic stroke (16\%)

strokes, $16 \%$ (8 patients), many small ischemic focus without ischemic stroke the results are shown in Figure 3. According to the Spearman correlation test, it was found a statistically significant correlation between the number of strokes and concentrations of homocysteine in the serum of patients with vascular dementia of $\mathrm{p}<0.05$ (correlation coefficient $=0.341, \mathrm{p}=0.015$ ). The serum homocysteine concentration is increasing with number of strokes infarctions and more ischemic focus.

\section{Discussion}

Homocysteine is an independent risk factor for developing peripheral vascular, cerebrovascular and coronary heart disease. The mechanism by which the total homocysteine may cause vascular disease includes thrombosis, endothelial dysfunction and increased oxidation of LDH (low density cholesterol) (15). About $50 \%$ of patients with hyperhomocysteinemia have vascular changes before ther thirty years of old (16). Our study showed that the group of patients with ischemic stroke 30\% (15 patients) had moderate hyperhomocysteinemia, from the total sample number it was $44 \%$ of men and $13 \%$ of woman. The results of our study have shown that the mean concentration of homocysteine after 24- 48 hours of hospital treatment was $13.27 \mu \mathrm{mol} / \mathrm{L}$, after 7 days $14.81 \mu \mathrm{mol} / \mathrm{L}$ and 14 day $16.93 \mu \mathrm{mol} / \mathrm{L}$ in comparison to serum concentration in control group it was $10.49 \mu \mathrm{mol} / \mathrm{L}$ (Table 1). At the post-acute phase of ischemic stroke after 7 days homocysteine increces for $1.54 \mu \mathrm{mol} / \mathrm{L}$ in compared to the concentration of homocysteine after the first 24-48 hours of patients hospitalization. In our study, after 14 days of hospitalization of patients with ischemic stroke average homocysteine concentration was increased from $0.20 \mu \mathrm{mol} / \mathrm{L}$ to $20.42 \mu \mathrm{mol} / \mathrm{L}$ (average $3.66 \mu \mathrm{mol} / \mathrm{L}$ ). The mean serum homocysteine concentration increases during first to second week for $2.12 \mu \mathrm{mol} / \mathrm{L}$. The results are shown in Figure 1 and Figure 2. In a two retrospective studies, the British regional health study and the Framingham Heart Study, that there is independent association betwe- 
en serum homocysteine and the incidence of ischemic stroke if homocysteine concentrations were equal or greater than $15.4 \mu \mathrm{mol} / \mathrm{L}$ and homocysteine concentrations were equal or greater than $14.24 \mu \mathrm{mol} / \mathrm{L}$. In the Rotterdam study it is showed a significant increase in stroke risk with increasing serum homocysteine levels above $18.6 \mu \mathrm{mol} / \mathrm{L}$ (17). High concentrations of homocysteine are closely correlated with the risk of silent stroke (18). It was concluded that homocysteine is an independent risk factor for stroke in people older than sixty years, and homocysteine concentrations above $14 \mu \mathrm{mol} / \mathrm{L}$ increased to $80 \%$ risk of stroke (19). If the concentration of serum homocysteine increases for 1 $\mu \mathrm{mol} / \mathrm{L}$ the risk for new ischemic stroke increases for $22 \%(20)$. The increase of homocysteine concentration for $5 \mu \mathrm{mol} /$ Lincreased the risk for coronary heart disease 1.6 times for men and 1.8 times for women, and cerebrovascular disease increases the risk for both sexes 1.5 times (21). It is believed that during the first week after ischemic stroke homocysteine concentration increases for about $10 \%$ (22). Our research has shown that during the first week after ischemic stroke, homocysteine concentration increases for about $11.6 \%$. Using Wilcoxon signed ranks the mean value of serum homocysteine in patients with ischemic stroke after 24-48 hours was significantly different than the mean values of homocysteine after 7 and 14 days of patients hospitalisation with significance of $p<0.05$. Our result have show using same test that there was a significant difference between the average homocysteine concentration after 7 and 14 days of hospital treatment $(\mathrm{p}<0.05)$ (Table 2). According to our results using the Mann-Whitney test average concentrations of homocysteine in the acute phase of ischemic stroke after 24-48 hours showed no significant difference with control group. A significant increase in homocysteine concentration occurs only in the acute phase in which there was a significant difference compared to the control group (Table 3). The results have shown that it is evident that the concentration of serum homocysteine increase after stroke. There are two possible explanations for the change in serum homocysteine concentration after acute phase and during the pos-tacute phase of ischemic stroke recovery: - The acute phase of ischemic stroke following stress which leads to short-term decrease in serum homocysteine. Damage to cerebral tissue increases the production of oxygen radicals, increases oxidative stress, leading to possible subsequent changes in the degree of elimination of thiols, including homocysteine.

- Serum homocysteine increases after the acute phase of ischemic stroke as a reason of folate and vitamins $\mathrm{B} 6$ or B12 deficiency which is particularly common in elderly people. Impairment of renal function also leads to increased concentrations of homocysteine (23).
Therefore, we excluded from our study patients with a high concentration of creatinine. The first early signs of dementia are presented with a reduction in the volume of brain mass and the occurrence of silent stroke (4). In our study, another group of patients who are determined homocysteine concentration had vascular dementia as a consequence of ischemic stroke. At group with vascular dementia hyperhomocysteinemia was present in $62 \%$ (81.4\% men and $39.1 \%$ women). According to our results in the group of patients with vascular dementia, the average homocysteine concentration was $20.39 \mu \mathrm{mol} / \mathrm{L}$. Homocysteine in the group of patients with vascular dementia was significantly higher than in the group with ischemic stroke and control group (Table 1). According to Mann-Whitney test for $\alpha=5 \%$, a significant difference between concentrations of homocysteine in the acute phase of ischemic stroke and vascular dementia. Using the same test for $\alpha=5 \%$, a significant difference between concentrations of homocysteine in the postacute phase of ischemic stroke and concentrations of homocysteine in vascular dementia. Comparing the results showed significant differences between the average concentrations of homocysteine with vascular dementia group and control group $(\mathrm{p}<0.05)$ (Table 3$)$. In the group of patients with vascular dementia, 52\% (26 patients) had one extensive stroke, $32 \%$ (16 patients) two, and $16 \%$ (8 patients), many small ischemic focus without ischemic stroke (Figure 3). We got significant correlation (Spearman correlation test) between the number of strokes and concentrations of homocysteine in the serum of patients with vascular dementia. The results of our study showed that with increasing number of attacks increased concentrations of homocysteine what can lead to evolution of vascular dementia after ischemic stroke. Our results shown that more males has hyperhomocysteinemia in relation to females, so they have move prevalence for developing new ischemic stroke or vascular dementia. If homocysteine concentration increases above $14 \mu \mathrm{mol} / \mathrm{L}$ increased the risk for Alzheimer's disease or vascular dementia for 4.6 times higher than in patients in who has concentration of homocysteine is less than $11 \mu \mathrm{mol} / \mathrm{L}$ (24). According to our results, homoysteine concentration increasing from acute to post-acute phase at patients with ischemic stroke and patients with vascular dementia have higher concentration of homocysteine then patients with ischemic stroke.

\section{Conclusion}

The homocysteine could be an independent risk factor for development of cerebrovascular disease. The possible limitation of of our study are limited number of patients and we have not informations about concentration of homocysteine before ischemic brain stroke or vascular dementia. Hyperhomocysteinemia is present in about 30\% (44\% men and 13\% females) of 
patients with ischemic stroke and in about $62 \%$ of patients with vascular dementia (81.4\% men and 39.1\% women). The concentration of homocysteine increases during 14 days of hospital treatment in comparison of homocysteine concentration 24-48 hours after ischemic stroke. The patients with elevated concentration of homocysteine after stroke have longer hospitalization than patients with reference value of homocysteine.

\section{References}

(1) Mcllroy SP, Dynan KB, Lawson JT, Petterson CC, Passmore AP. Moderately elevated plasma homocysteine, methylentetrahydrofolate reductase genotype, and risk for stroke, vascular dementia and Alzheimer disease in Northern Ireland. Stroke 2002; 33:2351-2356.

(2) Friedman AN, Bostom AG, Selhub J, Levey AS, Rosenberg IH. The Kidney and Homocysteine Metabolism. J Am Soc Nephrol 2001; 12:2181-2189.

(3) H faktor - može li krvni test spasiti život? 2004;(6)/04: Avaible at:http:// www. vasezdravlje. com/ izdanje/clanak/425/ (Accessed May 5, 2009).

(4) Bolander-Gouaille C, Bottiglieri T. Homocysteine related vitamins and neuropsychiatric disorders, 1 th ed. Springer-Verlag. France, 2007; pp. 1557,109-163

(5) Yoo JH, Chung CS, Kang SS. Relation of plasma homocysteine to cerebral infarction and cerebral atherosclerosis. Stroke 1998; (29): 2478-2483.

(6) Bots ML, Launer LJ. Homocysteine and short-term risk of myocardial infarction and stroke in the elderly: Rotterdam Study. Arch Intern Med 1999; (159):38-44

(7) Obeid R, Fassbender K, Herrmann W. Evaluation of current evidence on hyperhomocysteinaemia in neurological disease. Eur Neurol. Review 2008; 2-6.

(8) Kang S, Wong PWK. Genetic and nongenetic factors for moderate hyperhomocyst(e)inemia. Atherosclerosis 1996; (119):135-138.
(9) Weisberg IS, Park E, Ballman KV. Investigations of a common genetic variant in betaine-homocysteine methyltransferase (BHMT) in coronary artery disease. Atherosclerosis 2003; 167:205 214.

(10) 10. Van der Put NMJ, Van Straaten HWM, Trijbels FJM, Blom HJ. Folate, homocysteine and neural tube defects: an overview. Exp Biol Med 2001; 226:243-270.

(11) Herrmann W. The Importance of Hyperhomocysteinemia as a Risk Factor for Diseases: An Overview. Clin Chem Lab Med 2001; (39):666-674.

(12) Topić E, Primorac D, Janković S. Medicinskobiokemijska dijagnostika u kliničkoj praksi. Medicinska nakladaZagreb, Zagreb 2004; pp.27-32.

(13) Kuller LH, Evans RW. Homocysteine, vitamins, and cardiovascular disease. Circulation. 1998; 98:196-199.

(14) Dudman NP. An alternative view of homocysteine. Lancet. 1999; 354:20722074.

(15) Toole JF, Malinow RM, Chambless LE, Spence JD, Pettigrew LC, Howard VJ, Sides EG, Wang CH, Stampfer M. Lowering homocysteine in patients with ischemic stroke to prevent recurrent stroke, myocardial infarction and death. JAMA 2004; 291:565-575.

(16) Perry IV. Homocysteine, hypertension and stroke. J. Hum. Hypert.1999; 13:289-293.

(17) Sacco RL, Anand K, Lee HS, BodenAlbala B, Stabler S, Allen R, Paik MC. Homocysteine and the risk of ischemic stroke in a triethnic cohort. Stroke
2004; 35: 2263-2269.

(18) Toole JF, Malinow RM, Chambless LE, Spence JD, Pettigrew LC, Howard VJ, Sides EG, Wang CH, Stampfer M. Lowering homocysteine in patients with ischemic stroke to prevent recurrent stroke, myocardial infarction and death. JAMA 2004; 291:565-575.

(19) Stroke. 2007. www.medicine.ox.ac.uk/ bandolier/booth/hliving/homstroke.html - 10k (Accessed October 20, 2008)

(20) Atanassova PA, Angelova E, Tzvetanov P, Dimitrov SM. Modelling of increased homocysteine in ischaemic stroke: post-hoc cross-sectional matched case-control analysis in young patients. Arq. Neuro-Psiquiatr 2007;65 (1):2431.

(21) Kawamoto R, Kajiwara T, Yuichro O, Takagi Y. An associaton between plasma homocysteine concentration and ischemic stroke in elderly Japanese. J Atherotrombosis 2001; 9:121-125.

(22) Kelly PJ, Kistler JP, Shih VE, Mandell BA, Atassi N, Barron M, Lee H, Silvera S, Furie KL. Inflamation, homocysteine and vitamin $\mathrm{B} 6$ status after ischemic stroke. Stroke 2004; 35:12-15

(23) Lindgren A, Brattstrom L, Norrving B, Hultberg B, Andersson A, Johansson BB. Plasma homocysteine in the acute and convalescent phases after stroke. Stroke 1995; 26: 795-800.

(24) Stanger O. Homocystein grundlagen Klinik Therapie pravention. 1th ed.Verlag Wilheim Maudrich, WienMunchen-Bern 2004; pp. 43-49,157167. 